Canadian Journal of Action Research

Volume 22, Issue 1, 2021, pages 87-104

\title{
MOVING WITH THE MOVEMENTS: PARTICIPATORY ACTION RESEARCH IN/ACTION
}

Jonathan Langdon

St. Francis Xavier University

Natalie Krieger

St. Francis Xavier University

\author{
Sheena Cameron
}

OISE, University of Toronto

Alhassan Shani

Nanton District Assembly, Ghana

\begin{abstract}
Participation by its very nature is iterative, meaning Participatory Action Research (PAR) must be responsive to the way participation manifests and what actions emerge from this participation. In the article that follows, we share the complex and intertwined stories of PAR in action in two social movement contexts in Ghana, as well as the conditions that led to inaction in these two stories. This article builds on previous related work, where PAR was described as "moving with the movement" (Langdon \& Larweh, 2015), and describes the complexities of trying to move with the movement as conditions and relationships change over time. By sharing challenges and achievements that have emerged from the movement and research, we illustrate how moving with the movement has resulted in rich and unanticipated learnings.
\end{abstract}

KeY Words: Ghana; Participatory action research; Resource extraction; Social movement learning

\section{INTRODUCTION}

Participatory Action Research (PAR) is a research methodology rich in potential, but also in pitfalls. The way in which the methodology is designed and pursued is linked to the pitfalls and potentials that weave through the work. So too, though, are the conditions of the context and those involved in the research. PAR, by its very essence, is a dynamic methodology that resists a static research approach. Participation is iterative in nature, 
meaning PAR must be responsive to the way participation manifests and what actions emerge from this participation.

In the article that follows, we share complex and intertwined stories of PAR in action in two social movement contexts in Ghana, and we also share the conditions that led to inaction in these two stories. One movement is in Southern Ghana, in Ada, located in the Greater Accra region, while the other movement is in Northern Ghana, in Gbane, located in the Upper East region. In focusing on both sides of the PAR in action/inaction story, we aim to contribute to discussions of this research methodology that move beyond PAR being a panacea, on the one hand, and/or being too difficult to use, on the other. In effect, we build on previous related work, where PAR was described as "moving with the movement" (Langdon \& Larweh, 2015), and describe the complexities of trying to move with the movement as conditions and relationships change over time.

\section{PARTICIPATORY ACTION RESEARCH}

Participatory Action Research (PAR) combines two strands of engaged qualitative research: action research that builds on Kolb's (1984) cycle of action and reflection in engaged research, and participatory research that aims to make those at the centre of the research the main owners, designers and users of the research (Taggart, 1991). Glassman and Erden (2014) note further that a particular version of PAR emerged in the 1960s and 1970s from anti-colonial social movements in Africa, Asia, and Latin America, in particular. They add that Paolo Friere's ideas often informed the emergence of this research approach. As such, it is no surprise that in critical adult education circles that were largely inspired by Friere's work, PAR is recognized as a powerful way to engage in social movement learning study, as reflection and learning are built into the research cycle (Hall \& Turray, 2005). Social movement learning is considered an important area of study in critical adult education, focused as it is on better understanding how learning can contribute to socially just transformation (English \& Mayo, 2012). PAR has also been identified by Indigenous scholars as a potentially key methodology for decolonization (Tuhiwai-Smith, 1999). In fact, Fals Borda (2006), often credited with coining the term PAR, has underscored the relevance of PAR to movements in non-Western and Indigenous contexts.

At the same time, Fals Borda (2006) and other PAR researchers have cautioned against the rise in popularity of PAR, especially as it is taken up by such organizations as the World Bank (Jordan, 2003). Choudry and Kapoor (2010) raised similar concerns in social movement research, arguing PAR must be movement, as opposed to academic, led in order to avoid co-optation. To ensure it is collectively-owned movement-driven PAR, the design process must be done in partnership, and must continue to reflect on approach and process throughout (McTaggart, 1991). This ongoing dialogue throughout PAR is what Langdon has called "moving with the movement" (Langdon \& Larweh, 2015).

Moving with the movement means not only making adjustments to research, but to partnerships, depending on the way in which the movement struggle is evolving. Ongoing check-ins with those at the centre of the struggle is the only way to ensure the movement remains grounded. This has been a major learning point from this research. In the pages 
that follow, we trace how this learning has emerged in two above-mentioned social movement learning PAR contexts in Ghana.

\section{The Ada Songor Salt Movements}

The research involvement with the struggle in Southern Ghana, in Ada, emerged almost 15 years ago with an invitation to Langdon by activists struggling for return of communal access to West Africa's largest salt yielding lagoon, the Songor Salt Lagoon. Langdon met with members of the movement through the work of his participatory doctoral study of movement learning. These movement members then invited Langdon to work with them to document learning in the social movement. This invitation led to a co-design process, and nine years of SSHRC funded movement-articulated research. However, as Langdon and Larweh (2015) describe, this process was quickly subsumed in movement needs - the space of research discussion quickly became movement owned, with research documentation being a secondary concern. In this sense, the action-reflection cycle was sparked even at the co-design phase.

A crucial component of the ease in mobilization and trust in documentation was the ongoing involvement of Radio Ada - the local community radio that is a trusted ally of the dispossessed in Ada. Though this article will share some hurdles, as well as how they were overcome, the last 9 years has seen the research and movement relationship to be one of mutuality, where research contributes to movement work, and at the same time shares the story of Ada internationally. In recognition of the impact of this work, the research documentation has garnered two international research awards.

At the heart of the Ada Songor struggle is the cultural and spiritual connection of the Ada people to the 400-year old artisanal salt mining livelihood of the Songor Salt Lagoon, which has been continuously undermined and threatened by national development and private industry co-optation since colonization. After independence in the 1960s, Kwame Nkrumah's national development through the creation of the Volta River Dam hydro project drastically affected the natural water flow and salt creation within the lagoon (Government of Ghana, 1986). Additionally, it was over the next two decades that concessions were created that granted private companies access to, and subsequently profit off of, the lagoon, preventing local communal access and practicing of traditional rites (Secretaries' Committee of Ada Songor Cooperation, 1989). Furthermore, it altered the artisanal salt production, commodified the resource, involved secret deals with local traditional authorities by political parties, and resulted in security forces using inhumane methods to punish locals who dared assert their inherent traditional rights to the lagoon (Secretaries' Committee of Ada Songor Cooperation, 1989). These were the beginnings of the divisions that continue to exist in the community today.

During the 1980s, organized resistance at the community level, through a salt cooperative, ended with the tragic death of a pregnant woman, Maggie Kuwornor, and the wounding of others, from stray bullets from police attempting to repress local access to the lagoon (Secretaries' Committee of Ada Songor Cooperation, 1989). Additionally, many others were threatened, arrested, and tortured to discourage local resistance. Fortunately, these events 
resulted in a government inquiry, a halting of the private concessions, and the government creating legislation that enabled the national government to hold the resource in trust for the people of Ada. Unfortunately, attempts by the salt cooperative also resulted in failure when some of the executives were found to be mishandling the cooperative's finances and spent time in prison, effectively tainting the struggle.

The 2000s saw the re-emergence of many involved in the initial struggle but through a more participatory community approach, especially due to the involvement of the newly created community radio, Radio Ada. The movement attempted to hold the government accountable to legislation that held the resource in trust for the people and began to mobilize the community around a law (PNDC Law 287) which recommended the development of communal salt cooperatives while simultaneously opposing recommendations to privatize the lagoon once more (Ada Songor Advocacy Forum, 2016).

The current iteration of the movement is fighting state expropriation and local elite salt pan privatization (atsiakpo), which effectively limits local communal artisanal access to the salt lagoon, alters the lagoon's natural solar salt formation, and continues to impoverish communities that rely on the salt as their livelihood. Atsiakpo also increases divisions in the community and exacerbates and creates social problems such as gendered sexual exploitation, low education rates, and domestic violence. This participatory action research (PAR) began in 2010 with the Ada Songor Advocacy Forum (ASAF), but moved with the movement to work with the women who emerged as the strongest movement element, in partnership with Radio Ada. The women organized themselves into a network of executives, cluster leaders and community members, officially launching Yihi Katseme (Brave Women) in 2013. However, this did not come easy or without resistance within the movement.

\section{Challenges}

The most recent iteration of the women-led movement has encountered a variety of challenges. One such challenge has been the legacy of the former movement's male leadership which on occasion has resulted in older male activists trying to dominate issues or analysis, which has undermined the efforts of the Yihi Katseme and even created more obstacles for success.

\section{Struggles Within the Movement}

Leading up to the formal creation of Yihi Katseme, women had been at the forefront of the struggle and the most affected by the changes to the artisanal salt mining process, yet had been repeatedly undermined or excluded by some male leaders in the movement due to their gender and "literacy" levels (many of the women cannot speak English or are not formally-educated). The movement's challenging of these ideologies and the women's perseverance and resolve to be at the forefront of this struggle has altered the course of the movement. Women have navigated these hurdles as they are presented and have managed, with determination and skill, to overcome such challenges by utilizing their maternal wisdom and status. 
Still, there are actors that have disconnected from the current movement because they do not like that the Yihi Katseme (salt women) are leading the struggle, and they remain a potential threat to the movement's success. Some of these actors' continued involvement manipulates and undermines the efforts and inclusion of the Yihi Katseme by attending meetings and speaking for the Songor, misrepresenting and excluding the interests and voice of the women. No movement process is complete or without critique, with adversaries both internal and external. Therefore, acknowledging and working with these challenges becomes essential in "moving with the movement".

\section{Reliance on Movement Partners}

Furthermore, due to the well established relationships and strong advocacy of the community radio, an additional challenge has been the dependency of the movement on Radio Ada regarding community mobilization, dissemination of information, financial management, and organizational capacity. The participation of the community radio within the movement has strengthened the movement's effectiveness, yet has meant that the movement has not increased its independent capacity to withstand shocks or operations. This dependency extends to the internal sustainability of the movement on the research team for financial support over the years as well. However, recently, the Yihi Katseme executive have taken steps to rectify this by initiating proposals and internal membership fees, while maintaining strong ties to Radio Ada and recognizing the differing roles that different movement actors can and should play throughout the struggle.

\section{Achievements}

There have been many achievements worth noting, but perhaps the most significant is that the women have been accepted as legitimate defenders of the Songor Lagoon. This has solidified their status at the community, district, and national levels, and has enabled their participation in decision-making on different occasions and has meant they are sought after by the larger community to intervene in critical matters. Unfortunately, this also makes them a target, often receiving physical threats and being scapegoated by authorities, which is something they grapple with on an ongoing basis. Furthermore, this has not prevented the political leaders and traditional authority from ignoring their demands and leaving them out of decision-making that they know the Yihi Katseme would condemn.

\section{Creation of Pedagogical Spaces}

Moreover, in 2011, due to the movement's dissemination of information to communities that surround the lagoon and subsequent community mobilization, ASAF exposed the expropriation of the resource and plans for community relocation and alternative livelihood creation was stopped (ASAF, 2016). Community meetings by the movement exposed secret deals that demonstrated the corruption of some chiefs in their eagerness to make money at the cost of their own people (ASAF, 2016). The spaces of collective learning and community mobilization created in response to these government plans empowered community resistance and challenged neoliberal ideologies and institutions designed to undermine community self-determination. This example supports the work of Hall (2004), who explores how social movements are "pedagogical spaces for adults to learn to transform their lives and the structures around them" (p. 190). It further demonstrates 
how cognitive praxis constructs "knowledge on the basis of alternative values, challenging what is legitimated as knowledge and changing the way in which the world is known" as well as creating or reinvigorating collective identities (Scandrett et al., 2010, p. 126). The relationships between ASAF, Radio Ada, and the research team were crucial for this success.

The Yihi Katseme have also used songs as creative dissent to communicate things that cannot be spoken in other forms or as calls to action (Langdon 2020). This has been particularly effective by one member, Akpetiyo Larweh, who has become the Yihi Katseme's troubadour or trobairitz, composing and performing lyrical, poetic, prophetic and satirical songs regarding the Songor struggle (Langdon, 2020). Additionally, in 2012, a tapestry was created to capture the story of the Songor people and was used as a popular education tool, with many women being taught how to tell the story through a collective process and how to educate the broader Ada people at a local festival, Asafotufiami (Langdon \& Garbary, 2017). These examples also demonstrate Foley's (1999) term 'learning in struggle', demonstrating how PAR and social movement learning work symbiotically to move with movement struggles. Scandrett et al. (2010) suggest that social movements often become "epistemological communities engaged in the generation and distribution of knowledge, theory and culture through 'cognitive praxis' and the creation of spaces for social learning." (as cited in Lowan-Trudeau, 2017b, p. 98).

\section{Collective storytelling/symbolism}

Furthermore, within the movement, there have been numerous examples of how creative expression and radio broadcasts have been used to broaden movement knowledge over the years (Langdon et al., 2014). These include encouraging participants to use symbols or proverbs at group meetings to reflect on power dynamics, describe different actors, including themselves, or to describe and gain an in-depth understanding of different roles, actions or outcomes of participants or situations (Langdon et al., 2014). Hall (2009) explains that "social movement learning involves 'deconstructing relations of power' and through transformative resistance, the recovery of traditional wisdom and creation of new ideas and even societal institutions" is a resulting outcome (as cited in Lowan-Trudeau, 2017b, p. 97).

Symbolic and epistemically rooted pedagogic reflections are integral parts of locallyframed learning narratives. These narratives are adopted by the movement and become central to mobilization and education of community members. "The critical importance of local history and spirituality are also revealed to be key sites of epistemically grounded learning - learning that reinforces local ownership of this conversation in opposition to narratives of globalization and state-led visions of large-scale development" (Langdon et al., 2014). Below are quotes from community meetings held by the movement in $2011 / 2012$ that provided community members the space to choose symbols to represent their understanding of, and different actors within, the struggle for the Songor (Langdon et al., 2014). 
"For me, this whole thing is like somebody without thumbs, who is cutting morsels of food, he is hungry, but he wants to cut, you know, banku, you have to cut a morsel, and you need to roll it into a certain shape, before you can [eat it]... you need, you need a thumb... so for me it is a thumbless hand trying to mold a morsel of banku... So, we had, we had everything, but we lacked something, we lacked something to make our intentions and our aspirations complete. And, for me, the thumb is important." (Nomo Abayateye ${ }^{1}$, Traditional Priest, member of the older generation of male activists)

"The symbol that we selected was a chameleon, and, it was in reference specifically to the chiefs, who were participating in Atsiakpo, and to how the chiefs would be doing, some -, would be involved in Atsiakpo, but at the same time, like I mentioned, they would be saying "oh yes, Atsiakpo is very bad, I'm gonna stop it." And so, like the chameleon, they would be in one environment looking one way, but then they would change when they went to another environment, they would change their appearance." (Tom, representing youth activist group)

"What symbolizes the group's view?" We said dog. Our reason for choosing dog is that dog works for us, when we [are] going for hunting, take the dog along. When we need an animal to take care of our house, we take the dog. But what do we do to the dog? What, when we, even when we go to hunt with it, do we even give it the meat? After cooking, do you remove some meat for the dog? No! It's what we've chewed, the bones that you feed it with, that's what we do to the dog. So, that's it, that is what the Songor is." (Jemima, representing older generation of female activists)

Additionally, the creation of a collective book that was published in 2016, entitled Struggle of The Songor People, enabled different members of the community to provide their respective stories to tell the story of the Ada people and the Songor Salt Struggle, through a collective process which challenged the idea of "expert knowledge" and "whose knowledge counts" (ASAF, 2016; Langdon \& Larweh, 2015; Langdon \& Garbary, 2017). This project also supports the movement's philosophy that what one person does not know, another person knows, illustrating the importance of different perspectives and participatory storytelling to capture various elements of the same story.

In 2017, a drama piece was developed by the Ada people and performed on a number of occasions in Ada (and in Accra at the National Theater) to educate people about the complex elements of the Songor struggle and the effects on the Ada people. Furthermore, there have been numerous radio dramas and broadcasts produced and aired on Radio Ada, the local community radio station, in the local language, Dangbe. These broadcasts have created public awareness of the issues affecting the Ada people regarding the Songor

\footnotetext{
${ }^{1}$ Based on the requests of participants in the study we have kept their real names throughout the paper because they want to be associated and credited with their contributions.
} 
struggle. The role of Radio Ada has been pivotal in enhancing local ownership of and investment in the movement through radio dramas and community-owned broadcasts that disseminate narratives originating from the movements themselves. Such efforts demonstrate movement attempts to not only resist, but also revitalize and recreate the world as we want to see it. Finally, through a collective process, members of Yihi Katseme, Radio Ada, and the research team have developed a film that will be produced by a Ghanaian film crew, to capture the story of the Yihi Katseme and the Songor Salt movement as an additional tool for popular education of the Ada community, greater national audience, and internationally.

\section{The Relationships}

All of these examples have successfully created public awareness and popular education, strengthened the internal analysis and reflection of the movement, as well as created community cohesion. These actions have also produced and disseminated knowledge and restor(y)ed hope and resistance at various levels and in a diversity of ways (Langdon \& Garbary, 2017). This is similar to Graveline's (1998) assertion that "we learn in relationship to others, knowing is a process of 'self-in-relation'" (as cited in Kovach, 2009, p. 14). Furthermore, Hill and Stairs (2002) remind us of Freire's understanding that "knowledge is created and recreated in social interaction" and it can only be considered knowledge when it is manifested (p. 283).

Critical to these successes has been the developing and ongoing relationship-building between community members (namely ASAF, Yihi Katseme, and Radio Ada) and the research team. Using PAR, social movement learning, and moving with the movement, local movement narratives, decisions and actions have been driven by community actors and supported and documented by the research. The deep and long lasting relationships that have been built throughout this process, buttressed by this approach of "moving with the movement", have served as a linchpin in the action of this participatory action research. The research and movement relationship is one of mutuality, where research contributes to movement work, and the movement contributes to rich research, learning, and sharing.

\section{The Gbane/Talensi/Upper East Movements Against LaRge-Scale Mining}

Much like in the case of Ada, conversations in 2013 between Langdon and activists at the heart of a struggle to contest the presence of a Chinese owned mine in Gbane opened the door for research into movement-building and learning that was formalized in 2015. However, because the movement had largely de-mobilized in the intervening years, this research was co-designed with a partner organization, Northern Patriots in Advocacy and Research (NORPRA) who had been working with community and movement members on this issue since 2012. In an effort to emulate the success of the Radio Ada/Ada movement synergy, a local community radio station was also asked to join the research partnership. As the research in Gbane unfolded, unfortunately, this community radio station failed to fulfil its role in the research, which had major impacts on both the research and the struggle. At the same time, new activist mobilization that learned from the mistakes of the 2012-2013 effort have materialized. In 2019, a reset of the research, with these emergent 
movements at the centre of the work, is leading to very engaged and movement-owned Participatory Action Research.

The Gbane community in the Talensi district in Northern Ghana was founded in the late 1980s as a farming settlement. It has since emerged as one of the areas in the Upper East Region where artisanal gold mining is practiced. The artisanal gold mining dates back to the period when those from the area returned from working in mines (large scale and illegal small-scale) in the southern part of Ghana and became engaged in small-scale artisanal mining using traditional/rudimentary methods of extraction to mine for gold. This practice, popularly known as 'galamsey' in Ghanaian parlance, had become a major means of livelihood for many, especially the youth in the district, aside from agriculture. This practice was initially unregulated, and was described as illegal, especially in Southern Ghana where galemsey would often encroach on large-scale multinational corporationowned mines.

In 2006, the Government of Ghana passed the Minerals and Mining Act 2006 (Act 703), which allows Ghanaians (and only Ghanaians) the right to own small-scale mining concessions (Government of Ghana, 2006). Also, the Government of Ghana identified the Upper East Region as an area for small-scale mining (SSM) and demarcated the Gbane area in particular. This presented an opportunity for two Ghanaian based mining companies (Yenyeya and Pabortaaba Mining Groups) to each acquire a license for a 25 acre small-scale mine in the Gbane community. These two companies subsequently collaborated with a Chinese mining company known as Shaanxi Mining Company to provide mining support services (technical and logistical) for them to operate. This collaboration turned out to be the beginning of the woes of the Gbane community and the Talensi District.

The Shaanxi Mining Company started exploration and eventually moved into deep shaft large scale mining illegally, taking over the mining operations in the area but still operating under the SSM licensing and label. According to Crawford et al. (2015),

Shaanxi's mine on the 50 acre site involves one incline shaft and three vertical shafts that provide access deep underground to two main tunnels from where gold-bearing ore is extracted... A large, modern processing plant has also been constructed on the company's administrative and processing site, and the whole operation employs 450 staff, as of July 2014. (p. 16)

The result has been the dispossession of the Gbane community of their farmlands, pollution of water bodies, destruction of school buildings and people's houses (and other property) from the frequent blasts from the operations of the mining company. It has also led to the deaths of some illegal miners/'galamseyers' who were underground in their own pits mining for gold when cave-ins from Shaanxi's operations occurred. Recent revelations from the research indicate Shaanxi is not even sharing dividends with the local mine owners, claiming the mine has not yielded gold despite workers confirming weekly clandestine shipments of gold from the Shaanxi yard. Media stories have also surfaced that indicate Shaanxi is using its wealth to influence local judges and journalists (GhanaWeb, 2018). 
Some members of the Gbane community rose up in 2012 to fight the Shaanxi Mining Company and their local partners (Yenyeya and Pabortaaba Mining Groups), which led to the arrests of some prominent members of the struggle. The mine has also brought about divisions among the various clans of the Gbane community, based on those in favour and benefiting from the presence of the Chinese mining company and those who were negatively affected by it. These arrests and divisions demobilized the spontaneous movement in the years after the initial resistance. Adding fuel to the confusion, new foreign mining companies from Australia and the United Kingdom have emerged and started operations in the area.

Word of the 2012 struggle reached Langdon and his colleague. In 2013, they met with community members, leaders in the struggle, and with organizations working in the community including Northern Patriots in Advocacy and Research (NORPRA), to find out about the struggle, and to explore establishing a PAR study of movement learning in this struggle. This was met with interest, yet the arrests of struggle leaders, the demobilization of the movement against the mine, and divisions in the community led to the recommendation that NORPRA facilitate the research, as opposed to being led by community/movement members. When beginning the research in 2015 , a local community radio was also approached to become part of the team as a result of the success of the research in Ada. After initial design meetings with NORPRA and the community radio, the research began working with Gbane community members to better understand the struggles they face, and how the mine has affected them. As a result of the division in the community, the research team met with both sides of the community. In order to foster dialogue, a community radio program was proposed to community members. This was taken up, with women from both sides of the divide sharing songs in an effort to start dialogue, with hopes of reconciliation being expressed on both sides to provide a unified front to deal with the mine. While this program was initially broadcast by the community radio partner, the station stopped airing programs shortly thereafter, causing confusion and a lack of trust in the process to emerge. It remains unclear why this happened.

Parallel to this, new movements emerged in the area contesting Shaanxi's ongoing presence, as well as expressing concerns regarding new mining interests in the area. One of these movements, the Concerned Citizens of Talensi (the district Gbane is in) pushed the issue above Gbane, while another movement emerged from the small scale miners themselves, called the Small Scale Miners Association of the Upper East. These movements offered an opportunity for the research to "move with the movements" and re-center the research on the movements. Initial meetings held with the Concerned Citizens of Talensi in 2018 revealed deep learning from the 2012-2013 resistance to Shaanxi, and the subsequent divisions sown in the Gbane community and demobilization of the movement through the strategic arrests of movement leaders. The movement described their origin itself as one of the learnings - this issue is bigger than one community, and needs to be tackled by a movement with wider support. 
Consequently in 2019, the research held a redesign session with these movements, as well as journalists who had reported on mining malfeasance, even at the risk of their lives. The Trade Union Congress was also invited, as workers rights have also been undermined by Shaanxi. A guiding body was established to facilitate the research, made up of representatives from all the movements/groups involved in the meeting. NORPRA continues to convene this body, but is now guided by movement leadership in how learning is being documented and the action that is coming from this reflective process.

\section{Challenges \\ Movement dynamics shift meant community focus at research start}

Due to the shift in terrain between the first conversations with movement leaders and community members, and the subsequent start of the PAR in 2015, the approach used in Ada could not be pursued in Gbane. Movement activity was suspended, and divisions in Gbane itself were palpable. Therefore, the research co-design process occurred with organizational partners, rather than movement members. The focus of the initial stage of the work was to start community dialogue on learning from what had happened before. Although this effort did not yield immediate results, members of Concerned Citizens of Talensi have noted these conversations contributed to the beginning of this movement. Cabral's (1979) insights highlight the movement in movements that this shift in the social movement research in Gbane demonstrates, requiring an acknowledgement of movement "dynamism, both in action and in learning" (Langdon et al., 2020).

\section{Internal divisions and inaction}

The research was particularly challenged by the dormancy of the community radio partner to broadcast stories gathered from the community by research partners, which affected community relations. Furthermore, the community radio station did not cover issues relating to the socio-economic effects of large-scale foreign mining companies in the Talensi district and never broadcasted new stories relating to the Gbane mining incidents, even when private radio stations were doing so. This impacted the internal relations of the research team as it became clear that the community radio station did not share the vision of the research to support the social movement and community resistance to foreign mining in the Gbane community. Curnow and Helferty (2018) explain that tensions can arise within social movements when the goals of different groups are conflicted or not closely aligned. These effects also eroded the trust that the community had in the research and its partners and affected the PAR progress. Cabral (1979) reminds us of the importance of situating the analysis of this social movement struggle and social movement learning within the African context which helps to understand the conditions that impact movement actors and relationships. Particularly relevant is understanding the interlocking histories of colonialism and capitalism as well as their current bricolage and residual effects on individual and community actions and inactions under oppressive conditions (Harvey, 2004; Holst, 2002).

Furthermore, the internal divisions and obstacles for action within the Gbane community extended to cultural gender roles which excluded or marginalized women's voices at community meetings. In some cases, women who were vocal against Shaanxi were silenced 
by men, including their husbands. Gouin (2009) explains the interlocking oppressions that still exist within social movements and the interdependence of systems of domination that some social movement actors must learn to overcome. The learning connects culture, gender, race, political economy, and micropolitics to reflect on what sustains as well as transcends these systems. Since the Shaanxi mining activities directly impact women's livelihoods and increase social tensions, women's participation in the research is essential. However, this obstacle necessitated a different approach to the work of the research team to include and amplify women's voices, leading to a focus on the use of creative dissent in the form of songs and proverbs, similar to that of the Ada struggle.

\section{Achievements}

\section{Use of Songs/Proverbs to Unite Community}

Given the fact that the research strategy was reliant on a social movement-led process, it meant working to mobilize more support from the grassroots or citizens of the Gbane community to join existing/emerging movements in the struggle. It was, however, problematic due to the deep seated divisions among the four clans of the community. These divisions first needed to be addressed by the community themselves and solutions needed to be found in order to be able to forge ahead and address their common adversary; the effects of the large scale mining by Shaanxi. As a way of uniting the community, the research successfully documented the use of creative dissent in the form of songs and proverbs of the women of the community to address community division. Women's role within this process was central, yet as described above, included additional challenges. However, by using songs and proverbs, culturally relevant and effective in creating a space for women to be heard, the divisions were bridged in a more subtle manner. Furthermore, this approach enabled women to define and describe their world and challenge the structures of oppression, situating their "experience within a more nuanced social analysis" (Gouin, 2009, p. 172).

\section{Documenting learning of emergent coalition of movements and media}

Despite the failure of the community dialogue to lead to emergence of a unified movement at the Gbane community level, meetings with the Concerned Citizens of Talensi revealed significant movement learning, and provided the baseline of relationships necessary for the redesign process that emerged in 2019. Also, NORPRA has successfully documented the revelations of journalists concerning bribery efforts by Shaanxi and other mines, and has built relations with these journalists so that they were prepared to join the coalition that emerged from the 2019 meeting. Lowan-Trudeau (2017a) explains that social movements around the world "are currently resisting a wide array of natural resource developments that threaten both the cultural and ecological integrity of traditional territories" (p. 96). Furthermore,

This resistance takes many forms, ranging from protests and blockades; engagement with social, popular, and independent media; advocacy and legal action; artistic initiatives; reclamation and revitalization of cultural and ecological systems through land-based education; and, increasingly, the re- 
visioning of traditional knowledge and wisdom through community-based environmental initiatives. (Lowan-Trudeau, 2017a, p. 96)

These efforts require the collaboration of movement actors and supporters to take on various roles. It also requires an acceptance and understanding that movements will take many forms and in moving with the movement, each movement will look very different from another. Working with the Gbane community, social movements, NGOs, journalists

and the research team has created a diversity of actions and the rich documentation of efforts.

\section{Comparing And Contrasting Movements}

This section of the paper examines the similarities between both contexts of the study as well as examines the contrasts therein. Firstly, the crucial element in both contexts is a communal resource struggle by dispossession of the people by private, multi-national companies. In the Ada context, the struggle of the Songor Movement arose as a result of privatization and commercialization of a communal artisanal salt resource. Similarly, for the Gbane context, where national and international mining companies have dispossessed communities of their farmlands and lands with economic trees, such as shea, to engage in large scale deep shaft gold mining.

Furthermore, in both contexts, dispossession of communal resources resulted in a disgruntled and agitated citizenry which led to the emergence of social justice movements. In the Ada context, community radio was an important tool used in mobilizing the people to rise up. Also folklore and songs were greatly leveraged by the research in mobilizing the grassroots for action. This strategy was replicated in the Gbane context but was not very successful as a result of the ineffectiveness of the community radio partner.

Finally, an important similarity in both contexts was the infiltration by certain corrupt forces in government and private individuals into social movement leadership and community radio partners to undermine their struggle.

Fortunately, activities of external forces have not dampened the spirits of some leadership of social justice movements in both contexts. The struggle still continues for them as some protests, demonstrations, and court actions have been initiated and sustained which have led to some achievements being documented and lessons learnt therein for the future.

\section{What WE've LeARnED 'Moving WiTh THE Movements'}

Three significant learnings that members of the research team feel have emerged over the years must be mentioned. Most importantly, one that embodies the PAR approach and the concept of 'moving with the movements' is that ensuring that research is movement led is key to the ongoing success of the struggle. Foundational to these movements has been the lack of agenda-setting and intervening by the research team to meet predetermined goals or research outcomes. This does not mean that those of us actively involved did not provide support or advice along the way if it was invited or if knowledge or expertise in these areas was present. However, there was no intended research agenda aside from participating in 
movement activities and documenting the social movement learning process. This work requires "protesting ourselves", "reflexively considering our own habits and actions in light of those societal dynamics and practices against which we struggle" (Lowan-Trudeau, 2017b, p. 105). Despite the challenges that this approach creates for traditional notions of research, it results in a rich and enriching situation that allows movement paths and actions to emerge organically and unfold naturally. This also builds trust, openness, and capacity which resists historically extractive and subjective university research dynamics with communities.

The second learning interconnects with the first, which underscores the importance of trust in the capacity of the front line of the movement to lead the struggle without interfering or intervening from a point of ego or agenda as a member of the research team. This also requires a trust in our own capacity as a research team to support the work, knowing when to step up to take a lead to support and when to step back and provide behind the scenes support. The wisdom, humility, and ability to determine when this happens is both an internal process and a movement determined decision. The healthiest movements have developed a trust and openness to both silently and outwardly discuss these honestly to ensure the success of the movement. At different times and contexts, different people will play different roles, and trusting in the individual actors and this movement process is an important endeavor.

The third major learning through this work, for the research team particularly, is the commitment to relationships. As Brown (2017) explains, "the strength of our movement is in the strength of our relationships, which can only be measured by their depth" (p. 10). Especially important is the recognition that relationships are a process not an event, and they require ongoing mutual, reciprocal engagement and maintenance as well as an understanding of the relationships as dynamic and collaborative, not only inclusive. Furthermore, this includes understanding different roles of different members of the movement and knowing when to step up and when to step back, navigating when to take a leadership role and when to take a supporting role. This means a process of letting go of agendas, expectations or anticipated outcomes and ensuring that the work is communitydriven/community-led, including for our documentation. The community decides how their stories are defined, described and represented, particularly emphasizing desirecentered approaches instead of traditional damage-centered approaches (Tuck, 2009).

\section{CONCLUSION}

The dynamism of PAR as a methodology responds to the dynamism of social movements, resisting a static research approach by moving with the movement to ensure the research is responsive to the way participation manifests, what actions/inactions emerge, and owned by those struggling for progressive change. This requires a reflexive approach that is movement-led, refusing predetermined agendas and interference by the research team. This requires trust in the process, the movement, and the various actors involved as well as trusting different timing and the level of actors' leadership and supportive roles and ability to discern. It is the commitment to relationships as dynamic, collaborative, and inclusive throughout this process, acknowledging ongoing mutuality and reciprocity to maintain 
them that ground the success of PAR. The trust in these relationships allows for the openness, honesty, and vulnerability to ensure learning through struggle and moving with the movement, demonstrating that relationships are an integral part of the work.

The learnings that have emerged from these two social movement contexts and their action/inaction in Ghana are connected to the challenges and achievements of each context and the ability of the research partners to respond and move with the movement as conditions and relationships change over time. As internal movement divisions, challenges, and interlocking oppressions emerged, the research and movement participants responded with dynamic and creative strategies. These forms of creative dissent and expression resulted in rich and unexpected movement learning, the creation of pedagogical spaces, and important popular education and community mobilization. These became sites of collective and individual knowledge creation with incredible movement cohesion and action as well as exposing a lack of shared or aligned goals of movement partners. Embracing the different roles and dynamism of social movement and research partners, particularly the importance of community radio within these contexts, demonstrates the ways in which participants play a key role in the action/inaction of PAR and social movements. Without moving with the movement, none of these spontaneous learnings and successes would have emerged and the movements would not have responded to, or moved in, the directions they have. Using PAR to move with the movement has been met with potentials and pitfalls but has ultimately brought this research to unexpected places and resulted in rich and long lasting relationships.

\section{REFERENCES}

Ada Songor Advocacy Forum. (2016). The struggles of the Songor salt people. Accra: Comboni Printing School.

Brown, A. M. (2017). Emergent strategy: Shaping change, changing worlds. AK Press.

Cabral, A. (1979). Unity and struggle: Speeches and writings of Amilcar Cabral. Monthly Review Press.

Choudry, A., \& Kapoor, D. (2010). Learning from the ground up: Global perspectives on social movements and knowledge production. In A. Choudry \& D. Kapoor (Eds.), Learning from the ground up: Global perspectives on social movements and knowledge production (pp. 1-13). Palgrave Macmillan.

Crawford, G., Agyeyomah, C., Botchwey, G., \& Mba, A. (2015). The impact of Chinese involvement in small-scale gold mining in Ghana. International Growth Centre. Final Report E-33110-GHA-1

Curnow, J., \& Helferty, A. (2018). Contradictions of solidarity: Whiteness, settler coloniality, and the mainstream environmental movement. Environment and Society: Advances in Research, 9, 145-163. 
English, L. M., \& Mayo, P. (2012). Learning with adults: A critical pedagogical introduction. Sense Publishers.

Fals Borda, O. (2006). The north-south convergence: A 30 year personal assessment of PAR. Action Research, 4(3), 351-358.

Foley, G. (1999). Learning in social action: A contribution to understanding informal education. Zed Books.

GhanaWeb. (Dec 18, 2018). Judge recuses himself as Shaanxi officials attempt to bribe journalist. https://bit.ly/3jptF5v

Glassman, M., \& Erdem, G. (2014). Participatory action research and its meanings: Vivencia, praxis, conscientization. Adult Education Quarterly, 64(3), 206-221

Gouin, R. (2009). An antiracist feminist analysis for the study of learning in social struggle. Adult Education Quarterly, 59(2), 158-175.

Government of Ghana. (1986). The Amissah Commission Report. Accra: Assembly Press.

Government of Ghana. (2006). Minerals and Mining Act. Accra: Assembly Press.

Hall, B. (2004). Towards transformative environmental adult education: Lessons from global social movement contexts. Counterpoints, 230, 169-191

Hall, B. (2009). A river of life: Learning and environmental social movements. Interface: A Journal for and about Social Movements, 1(1), 46-78.

Hall, B. L., \& Turray, T. (2006). A review of the state of the field of adult learning: Social movement learning. Canadian Council of Learning. http://en.copian.ca /library/research/sotfr/socialmv/socialmv.pdf

Harvey, D. (2004). The 'new' imperialism: Accumulation by dispossession. Socialist Register, 40, 63-84.

Hill, J. C., \& Stairs, A. H. (2002). Editorial. Indigenous education: Ways of knowing, thinking, and doing. McGill Journal of Education, 37(3), 281-285.

Holst, J. D. (2002). Social movements, civil society, and radical adult education. Bergin \& Garvey.

Jordan, S. (2003). Who stole my methodology? Co-opting PAR. Globalisation, Societies and Education, 1(2), 185-200.

Kolb, D. (1984). Experiential learning: Experience as the source of learning and development. Prentice Hall. 
Kovach, M. (2009). Indigenous methodologies: Characteristics, conversations, and contexts. University of Toronto Press.

Langdon, J. (2020). African social movement learning: Case of Ada salt movement in Ghana. Brill Sense Publisher.

Langdon, J., \& Garbary, R. (2017). Restor(y)ing hope: Stories as social movement learning in Ada Songor salt movement. Education as Change, 21(3), 1-18.

Langdon, J., Jackson, M., \& Kitcher, S. (2020). Pedagogy of song and restor(y)ing hope: Stories and songs as social movement learning in Ada Songor salt movement. In F. Finnegan \& B. Grummell (Eds.), Doing creative and critical research in adult education (pp. 167-176). Bill Sense Publisher.

Langdon, J., \& Larweh, K. (2015). Moving with the movement: Collaboratively building a participatory action research (PAR) study of social movement learning in Ada, Ghana. Action Research, 13(3), 281-297. https://doi.org/10.1177/14767 50315572447

Langdon, J., Larweh, K., \& Cameron, S. (2014). The thumbless hand, the dog and the chameleon: Enriching social movement learning theory through epistemically grounded narratives emerging from a participatory action research case study in Ghana. Interface, 6(1), 27-44.

Lowan-Trudeau, G. (2017a). Gateway to understanding: Indigenous ecological activism and education in urban, rural, and remote contexts. Cultural Studies of Science Education, $12,119-128$.

Lowan-Trudeau, G. (2017b). Protest as pedagogy: Exploring teaching and learning in Indigenous environmental movements. The Journal of Environmental Education, 48(2), 96-108.

McTaggart, R. (1991). Principles of participatory research. Adult Education Quarterly, 41(3), 168-187.

Secretaries' Committee of Ada Songor Cooperation. (1989). Who killed Maggie? The story of the Songor Lagoon. In cooperation with The Africa Centre, Cadier en Keer, BijEEN,'sHErtogenbosch. https://opendocs.ids.ac.uk/opendocs/handle/20.500.12413/1200

Scandrett, E., Crowther, J., Hemmi, A., Mukherjee, S., Shah, D., \& Sen, T. (2010). Theorising education and learning in social movements: Environmental justice campaigns in Scotland and India. Studies in the Education of Adults, 42(2), 124-140.

Tuck, E. (2009). Suspending damage: Letter to communities. Harvard Educational Review, $79(3), 409-427$.

Tuhiwai-Smith, L. (1999). Decolonizing methodologies: Research and Indigenous people. Zed Books \& University of Otago Press. 


\section{BIOGRAPHICAL NOTE:}

Jonathan Langdon is an Associate Professor and Canada Research Chair in Sustainability and Social Change Leadership at St. Francis Xavier University in Antigonish, Nova Scotia. He has been working with social movements in Ghana for the last 19 years, and more specifically with a movement in Ada defending communal access to a salt yielding lagoon since 2008. His recent work connects with other resource contention hot spots in Ghana, as well as with Indigenous Mayan educators/activists in Guatemala. He also works closely with climate justice movements and Mi'kmaq First Nation Water Protectors in Nova Scotia).

Sheena Cameron has been engaged in community development, solidarity and experiential learning in Canada, Ghana and Guatemala for the last 18 years and has worked with this PAR work in Ghana since 2012 as a research assistant. She holds a Masters in Communication and Social Justice from the University of Windsor focusing on media representation of the Canadian mining industry's activities abroad and community resistance. She is currently pursuing her PhD in Social Justice Education at OISE, University of Toronto focusing on Indigenous and non-Indigenous partnerships within the climate/environmental justice movement. She has also been a part-time lecturer in the Development Studies program at St. Francis Xavier University since 2014.

Natalie "nat" Krieger (she/they) has a B.A. in Aquatic Resources from St. Francis Xavier University. She spent the summers (Ghana rainy seasons) of 2018 and 2019 in Ada, Ghana with Radio Ada and the Yihi Katseme supporting and documenting their struggle for the Songor Salt Lagoon on this participatory action research (PAR). Their undergraduate research focuses on the salt politics and Indigenous resource management techniques preserved by artisanal salt winners within the Songor Lagoon of Ada, Ghana. She is particularly interested in ecofeminism, deep ecology, and community radio as a form of activism.

Mr. Alhassan Shani is a development practitioner based in the Tamale, Ghana with an accumulated seven years of experience working in development research, community mobilization, social accountability, monitoring and evaluation of projects and development planning process. He is currently a Deputy Development Planning Officer in the Nanton District Assembly in Northern Ghana. Alhassan's development orientation is firmly rooted in participatory development. Additionally, he is passionate about research that encourages community participation, learning and action. 